\title{
Dynamical evolution of North Atlantic ridges and poleward Jet Stream displacements
}

Article

Published Version

Woollings, T., Pinto, J. G. and Santos, J. A. (2011) Dynamical evolution of North Atlantic ridges and poleward Jet Stream displacements. Journal of the Atmospheric Sciences, 68 (5). pp. 954-963. ISSN 1520-0469 doi:

https://doi.org/10.1175/2011JAS3661.1 Available at https://centaur.reading.ac.uk/32766/

It is advisable to refer to the publisher's version if you intend to cite from the work. See Guidance on citing.

Published version at: http://dx.doi.org/10.1175/2011JAS3661.1

To link to this article DOI: http://dx.doi.org/10.1175/2011JAS3661.1

Publisher: American Meteorological Society

All outputs in CentAUR are protected by Intellectual Property Rights law, including copyright law. Copyright and IPR is retained by the creators or other copyright holders. Terms and conditions for use of this material are defined in the End User Agreement.

www.reading.ac.uk/centaur 
Central Archive at the University of Reading

Reading's research outputs online 


\title{
Dynamical Evolution of North Atlantic Ridges and Poleward Jet Stream Displacements
}

\author{
TiM WOOLLINGS \\ Department of Meteorology, University of Reading, Reading, United Kingdom \\ JOAQUim G. PINTO \\ Institute for Geophysics and Meteorology, University of Cologne, Cologne, Germany \\ Jỗo A. SANTOS \\ CITAB, Department of Physics, University of Trás-os-Montes and Alto Douro, Vila Real, Portugal
}

(Manuscript received 2 September 2010, in final form 14 December 2010)

\begin{abstract}
The development of a particular wintertime atmospheric circulation regime over the North Atlantic, comprising a northward shift of the North Atlantic eddy-driven jet stream and an associated strong and persistent ridge in the subtropics, is investigated. Several different methods of analysis are combined to describe the temporal evolution of the events and relate it to shifts in the phase of the North Atlantic Oscillation and East Atlantic pattern. First, the authors identify a close relationship between northward shifts of the eddydriven jet, the establishment and maintenance of strong and persistent ridges in the subtropics, and the occurrence of upper-tropospheric anticyclonic Rossby wave breaking over Iberia. Clear tropospheric precursors are evident prior to the development of the regime, suggesting a preconditioning of the Atlantic jet stream and an upstream influence via a large-scale Rossby wave train from the North Pacific. Transient (2-6 days) eddy forcing plays a dual role, contributing to both the initiation and then the maintenance of the circulation anomalies. During the regime there is enhanced occurrence of anticyclonic Rossby wave breaking, which may be described as low-latitude blocking-like events over the southeastern North Atlantic. A strong ridge is already established at the time of wave-breaking onset, suggesting that the role of wave-breaking events is to amplify the circulation anomalies rather than to initiate them. Wave breaking also seems to enhance the persistence, since it is unlikely that a persistent ridge event occurs without being also accompanied by wave breaking.
\end{abstract}

\section{Introduction}

In the midlatitudes of the Northern Hemisphere, daily weather changes can often be related to the passage of (anticyclonic) high and (cyclonic) low pressure systems (Wallace et al. 1988). The establishment of more persistent blocking or blocking-like situations is of particular interest as it implies an important change in the large-scale circulation, which strongly affects both the weather conditions over the affected area and the shortterm weather predictability. Recently, Santos et al. (2009)

Corresponding author address: Tim Woollings, Department of Meteorology, University of Reading, Earley Gate, P.O. Box 243, Reading RG6 6BB, United Kingdom.

E-mail: t.j.woollings@reading.ac.uk analyzed the occurrence of strong and persistent ridge events (SPREs) over the southeastern North Atlantic and described the associated large-scale meteorological conditions. SPREs are commonly characterized by a strengthening of the North Atlantic ridge, a northward shift of the North Atlantic storm track, and an enhanced diffluence of the subtropical and eddy-driven westerly jets over the North Atlantic. During SPREs there is also clear evidence for a warm-core equivalent barotropic structure in the North Atlantic ridge throughout the troposphere. While SPREs do not represent a blocking situation per se (which typically occurs at higher latitudes), the large-scale westerly flow is effectively blocked at lower latitudes over the North Atlantic during these events, often leading to drought conditions in Iberia. 
Santos et al. (2009) also gave an example of a recent SPRE event in which the characteristic meridional overturning signature of anticyclonic wave breaking was apparent. Several recent studies have linked Rossby wave breaking (RWB) with latitudinal shifts of the jet stream, but these have generally focused on the development of different phases of the North Atlantic Oscillation (NAO; e.g., Feldstein 2003; Benedict et al. 2004; Martius et al. 2007; Rivière and Orlanski 2007; Kunz et al. 2009a). While the NAO is the dominant pattern of atmospheric circulation variability over the North Atlantic, it does not describe all variations of the jet stream. In particular, the East Atlantic (EA) pattern often emerges as the second most important pattern of variability, and this also describes changes in the jet stream. In fact, variations in both jet latitude and speed can be described with a combination of the NAO and EA, and these kinematic quantities are not uniquely related to individual spatial patterns (Monahan et al. 2009; Woollings et al. 2010b).

Woollings et al. (2010b) suggested that there are three preferred positions of the jet stream: southern, central, and northern. In periods when the jet is in its northern position, the storm track is diverted north of Iberia and there is enhanced occurrence of RWB over the southeast North Atlantic, so it seems likely that SPREs coincide with these periods. This situation corresponds to the negative phase of the EA, as well as a weakly positive NAO. Similarly, Santos et al. (2005) showed that precipitation in Portugal is linked not only to the NAO pattern (NAO+ and NAO- precipitation regimes), but also to the EA pattern ( $\mathrm{C}$ and $\mathrm{E}$ regimes). In fact, precipitation in Portugal is mostly related to a dipolar pattern similar to the NAO pattern, but shifted northeast by about $15^{\circ}$ of latitude (Ulbrich et al. 1999). As shown by Woollings et al. (2010b), such shifted NAO patterns reflect a combined loading of both the NAO and the EA.

Since northward shifts of the jet project most strongly onto the EA, their dynamics have not been specifically addressed in the many studies that focus on the NAO. The first aim of this paper is to compare the occurrence of SPREs with indices of RWB and jet stream latitude, in order to determine whether these features do coincide with the occurrence of SPREs in general. In addition, we analyze the role of transient eddy forcing and RWB in the evolution and maintenance of SPREs, with the hope that the timing of the dynamical events may provide indications of cause and effect.

The next section describes the 40-yr European Centre for Medium-Range Weather Forecasts (ECMWF) ReAnalysis (ERA-40) dataset, the SPRE classification, the jet latitude, and the RWB indices. Section 3 characterizes the SPRE events in terms of jet regime and RWB events, their temporal evolution, and the associated dynamics. A short discussion concludes this paper.

\section{Data and methods}

We use data from the ERA-40 (Uppala et al. 2005) available on a $1.125^{\circ}$ latitude $\times 1.125^{\circ}$ longitude grid. We focus on the winter period [December-February (DJF)], as this is the season when the large-scale circulation anomalies are strongest and have the most influence on regional climate. Altogether there are 44 complete winter seasons (1957/58-2000/01). Additionally, we consider the National Centers for Environmental Prediction-National Center for Atmospheric Research (NCEP-NCAR) reanalysis data (Kistler et al. 2001, hereafter NCEP) to compare the SPRE statistics with previous results (Santos et al. 2009). This dataset has a spatial resolution of $2.5^{\circ}$ latitude $\times 2.5^{\circ}$ longitude and was considered for the same 44 winters. Both datasets are available every $6 \mathrm{~h}$.

SPREs were originally defined by Santos et al. (2009). Here, we introduced some slight modifications to their definition in order to become more consistent with the RWB identification methodology. SPREs are considered as an uninterrupted sequence of 10 strong ridge days that are preceded by at least 5 days without a strong ridge. Each strong ridge day is characterized by a zonalmean departure in the $250-\mathrm{hPa}$ geopotential height, averaged over the sector $40^{\circ}-50^{\circ} \mathrm{N}, 40^{\circ} \mathrm{W}-5^{\circ} \mathrm{E}$, above the corresponding median (computed for all selected winters). Daily departures from the curve of the corresponding long-term daily zonal means (1957-2001), previously smoothed by a second-order polynomial, are considered. In the previous definition (Santos et al. 2009), a minimum interruption of 3 days had been considered (instead of the 5 days used here), and the analyzed isobaric surface was $300 \mathrm{hPa}$ (here $250 \mathrm{hPa}$ ).

In addition, large-scale circulation anomalies will be described using some dynamically motivated indices. First, we will use the jet stream latitude index of Woollings et al. (2010b). This index uses the zonal wind from pressure surfaces between 925 and $700 \mathrm{hPa}$. By focusing on the low-level wind this method identifies the eddy-driven jet stream specifically, rather than the subtropical jet, which is only strong at upper levels. Full details are given by Woollings et al. (2010b), but the method essentially identifies the latitude of the maximum zonal wind in an average over the Atlantic sector $0^{\circ}-60^{\circ} \mathrm{W}$.

Second, we use the two-dimensional RWB index of Woollings et al. (2008). This is an extension of the onedimensional blocking index of Pelly and Hoskins (2003). The index searches for reversals of the negative meridional gradient of potential temperature on the dynamical 
TABLE 1. SPREs onset and decay days, along with their lengths. Results obtained for ERA-40 reanalysis and for NCEP-NCAR reanalysis (between parentheses when different). There is a total of 378 (377) SPRE days in the ERA-40 (NCEP) dataset.

\begin{tabular}{|c|c|c|c|c|c|c|c|}
\hline \multirow[b]{2}{*}{ SPRE } & \multicolumn{3}{|c|}{ Onset } & \multicolumn{3}{|c|}{ Decay } & \multirow{2}{*}{$\begin{array}{l}\text { Length } \\
\text { (days) }\end{array}$} \\
\hline & Day & Month & Year & Day & Month & Year & \\
\hline 1 & 30 & Jan & 1967 & 10 & Feb & 1967 & 11 \\
\hline 2 & 17 & Dec & 1967 & 29 & Dec & 1967 & 12 \\
\hline 3 & 2 & Feb & 1971 & 14 & Feb & 1971 & 12 \\
\hline 4 & 22 & Jan & 1973 & 9 & Feb & 1973 & 18 \\
\hline 5 & 26 & Dec & 1974 & 10 & Jan & 1975 & 15 \\
\hline 6 & 19 & Dec & 1975 & 25 & Jan & 1976 & 37 \\
\hline 7 & 23 & Dec & 1977 & $8(7)$ & Jan & 1978 & $16(15)$ \\
\hline 8 & 9 & Dec & 1980 & 2 & Feb & 1981 & 65 \\
\hline 9 & 21 & Jan & 1982 & 2 & Feb & 1982 & 12 \\
\hline 10 & 25 & Dec & 1983 & 18 (19) & Jan & 1984 & $24(25)$ \\
\hline 11 & 9 & Jan & 1986 & 27 & Jan & 1986 & 18 \\
\hline 12 & 16 & Jan & 1987 & 27 & Jan & 1987 & 11 \\
\hline 13 & 17 & Dec & 1987 & 3 & Jan & 1988 & 17 \\
\hline 14 & 6 & Jan & 1990 & 18 & Jan & 1990 & 12 \\
\hline 15 & 19 & Dec & 1992 & 29 & Dec & 1992 & 10 \\
\hline 16 & 15 & Jan & 1994 & 3 & Feb & 1994 & 19 \\
\hline 17 & 9 & Dec & 1994 & 28 & Dec & 1994 & 19 \\
\hline 18 & 5 & Feb & 1998 & 20 & Feb & 1998 & 15 \\
\hline 19 & 11 & Feb & 2001 & $24(23)$ & Feb & 2001 & $13(12)$ \\
\hline 20 & 5 & Feb & 2002 & 27 & Feb & 2002 & 22 \\
\hline
\end{tabular}

tropopause, defined by the 2-potential vorticity unit (PVU; $1 \mathrm{PVU} \equiv 10^{-6} \mathrm{~m}^{2} \mathrm{~s}^{-1} \mathrm{~K} \mathrm{~kg}^{-1}$ ) surface. Temporal and spatial scaling is then applied to ensure that any feature identified is large scale, quasi-stationary, and persistent (lasting at least 5 days). The persistence criterion, in particular, means that the events identified can be considered as blocking, or so-called high-latitude blocking events, and distinguishes this index from others that identify more transient features. We use the set of events identified as $R W B$ episodes in ERA-40, following the definitions given in Woollings et al. (2008).

\section{Results}

\section{a. Characterization of SPRE events in terms of jet regime and $R W B$}

The modified SPRE algorithm was applied to ERA-40 data to enable a comparison with the RWB analysis. Next, the events were similarly identified in NCEP data for easier comparison with previous results (Santos et al. 2009). It was found that identified SPREs are virtually identical to those found in the previous study, so a detailed discussion of the results is omitted. Regarding the ERA-40 and NCEP, and despite the different resolution, results are highly consistent: Table 1 lists the 20 SPREs (onset, decay, and length) identified using both reanalysis datasets, with a total of 378 (377) SPRE days for ERA-40 (NCEP). Only minor differences are found

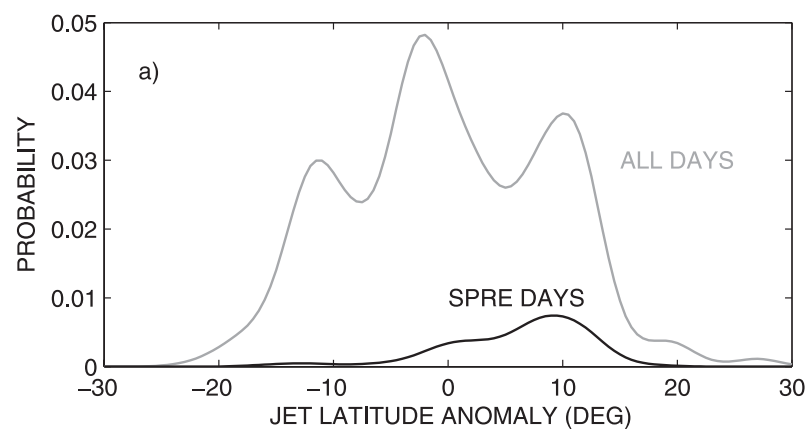

Daily NAO / EA scatter with ridge days in black

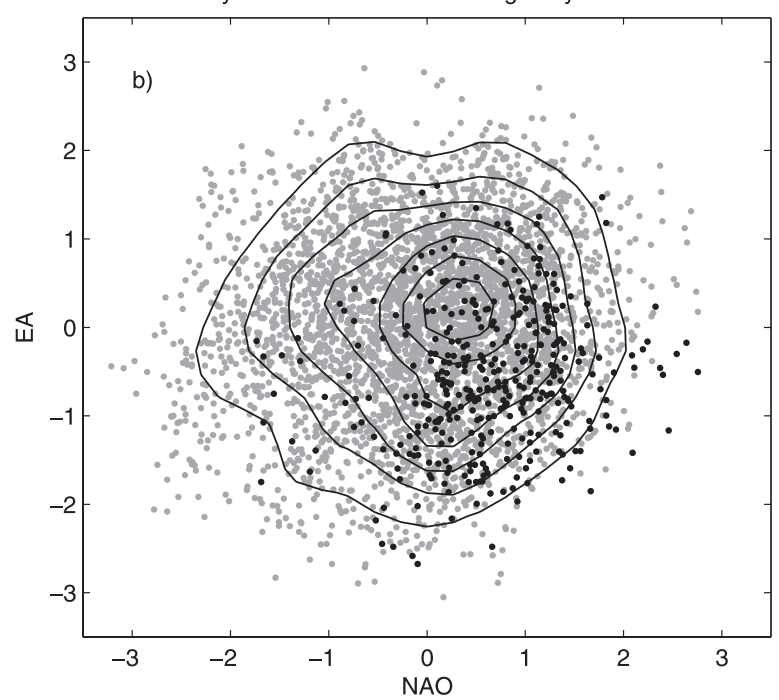

FIG. 1. (a) Link between SPRE and three jet regimes from Woollings et al. (2010b). (b) Scatterplot for daily mean NAO vs EA phases. Ridge days are in black, and contours show density as in Woollings et al. (2010b).

in three of the decay dates (1-day lags), while the onsets are entirely independent of the dataset. This close agreement between both datasets is not surprising, as the SPRE are mostly associated with very large-scale features. In this section we compare these events with other diagnostics of large-scale flow variations.

The North Atlantic eddy-driven jet stream is arguably the single most important factor influencing the weather in western Europe, so we begin by considering the diagnostic of the latitude of the Atlantic eddy-driven jet as defined by Woollings et al. (2010b). Figure 1a shows the distribution of the jet latitude anomaly for all winter days, which clearly shows three preferred positions of the jet stream. The black line shows the same quantity, but plotted only for those days that are identified as SPRE days in ERA-40. This reveals that SPRE days occur mostly when the jet is in its northernmost position. Woollings et al. (2010b) also showed that the variability of the jet can be summarized by the two-dimensional state space defined by the NAO and the EA. Figure $1 \mathrm{~b}$ 
shows a scatterplot of the daily winter data in this state space, with the SPRE days highlighted in black. Again there is a clear signature, with SPRE days occurring almost exclusively in the positive NAO region and preferentially when the EA is negative, in agreement with Santos et al. (2005). This confirms that SPRE events are associated with large-scale displacements of the eddydriven jet stream, specifically with the northern jet regime described by Woollings et al. (2010b).

Finally, we compare SPRE events to the occurrence of RWB episodes. Figure 2 a shows the occurrence of RWB contemporaneous with the occurrence of SPREs, and Fig. 2 b depicts this as an anomaly from the climatology. Results show enhanced occurrence of RWB over and near Iberia during SPRE days, which is a clear indication of a connection between the two phenomena. The reduced occurrence of RWB to the north of this reflects the fact that the meridional gradient will be strengthened on the northern side of the anticyclonic anomaly, rather than reversed. As seen in Woollings et al. (2010b; their Fig. 7), RWB occurrence over the southeastern North Atlantic generally coincides with the northern jet regime.

The SPRE events are therefore associated both with shifts of the eddy-driven jet and with the occurrence of upper-tropospheric RWB. We now investigate how the events identified by these methods differ. First, Fig. 1 shows that there are relatively few SPRE days compared to the number of days when the jet is in its northern position. It is also clear from this figure that the flow anomaly during SPREs, either in jet latitude or in the $\mathrm{NAO} / \mathrm{EA}$ space, is not larger than during other northern jet days. This suggests that the characteristic that distinguishes SPREs from other northern jet events is their persistence, rather than their amplitude. This could be expected given the definition of SPREs, with its emphasis on persistence.

To investigate the difference between SPRE and RWB events we need to identify the RWB events of interest. To do this we define a region $\left(35^{\circ}-45^{\circ} \mathrm{N}, 0^{\circ}-\right.$ $30^{\circ} \mathrm{W}$ ) and identify a sector RWB episode when there is an RWB episode covering at least one point of this region. We will refer to these sector RWB episodes as Iberian wave breaking, or IWB events, of which there are 72 in the 44 winters considered. The longest of the SPREs is associated with 4 distinct IWBs, but this extremely long (65 day) event is clearly unusual. In total we have identified 17 SPREs with at least 1 IWB and 4 SPREs with at least 2 IWBs. For only 3 of the SPREs was no IWB identified. To summarize, almost all of the SPREs are associated with an IWB, but the multiple occurrence of distinct IWB within the duration of one SPRE is quite rare. This suggests that it is unlikely that (a)

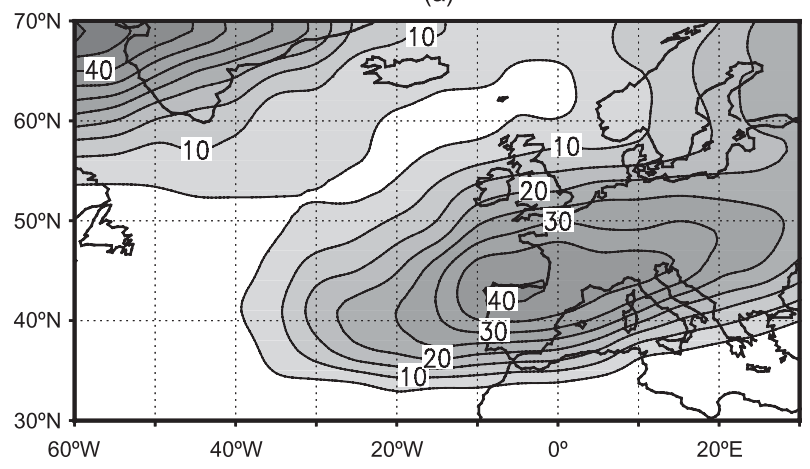

(b)

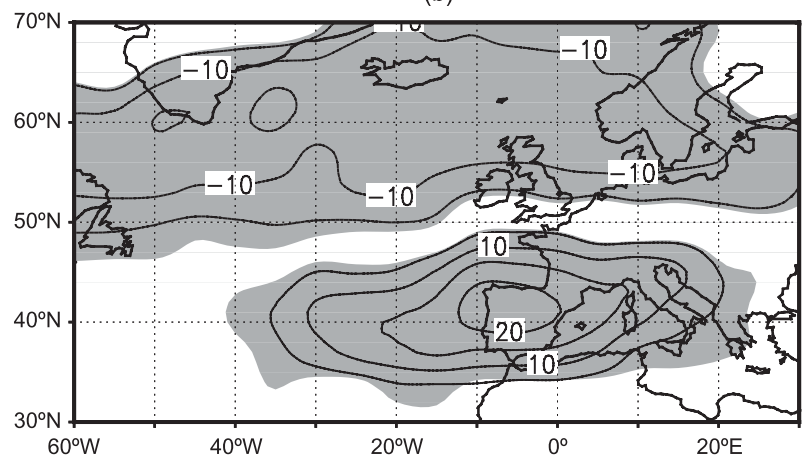

FIG. 2. (a) Percentages of RWB occurrence during SPRE days. (b) Difference between (a) and the corresponding baseline climatology (contours). Statistically significant anomalies at the $95 \%$ confidence level of the Student's $t$ test are shaded.

a ridge will persist for long enough to count as a SPRE without the occurrence of IWB.

Figure 3 illustrates the differences between the 2 sets of events by showing composites of potential temperature $\theta$ on the 2-PVU surface for all SPRE days and for SPRE days with and without IWB events. The composite for all SPRE days (Fig. 3a) shows the subtropical and eddy-driven jet streams (as tight meridional $\theta$ gradients) split around an anticyclonic anomaly in the east Atlantic. Compared to days without an accompanying IWB episode (Fig. 3c), those with both a SPRE and an IWB occurrence (Fig. 3b) exhibit a more pronounced split between the jet streams. IWB therefore enhances the flow configuration associated with SPREs. The jet diagnostics support the impression given here that the eddydriven jet is stronger and displaced farther north when an IWB episode accompanies a SPRE, although this difference is small compared to the variability between events (not shown). The overturning of $\theta$ contours associated with the IWB is clear in Fig. 3b, indicating easterly flow in the eastern North Atlantic. The wave breaking is clearly anticyclonic in nature, in agreement with Santos et al. (2009) and also the wave-breaking morphology studies of Tyrlis and Hoskins (2008) and Gabriel and Peters (2008). 
a) THPV2 composite: ALL SPRE

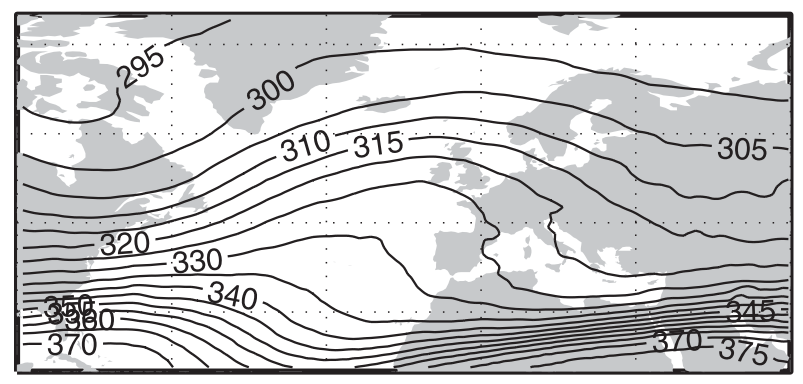

b) THPV2 composite: SPRE AND IWB

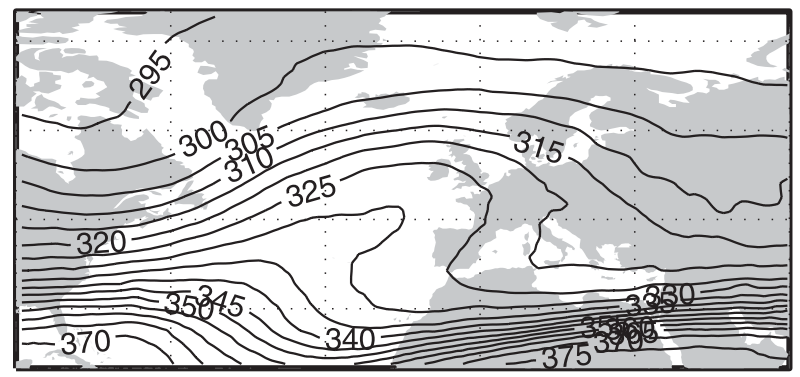

c) THPV2 composite: SPRE NOT IWB

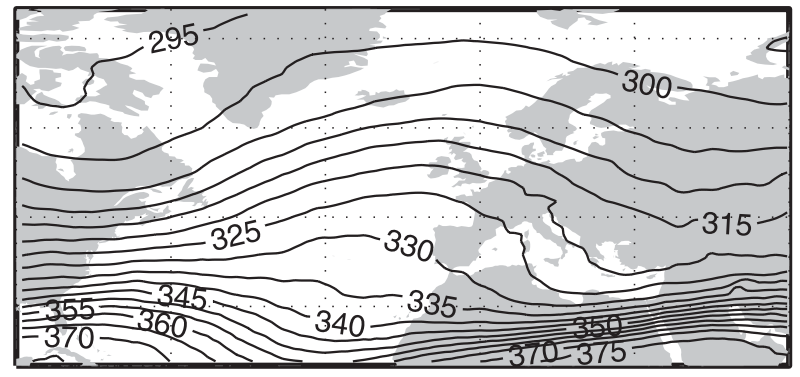

FIG. 3. Composites of potential temperature (K) on the 2-PVU surface for the sets of days with (a) SPREs, (b) SPREs and IWBs, and (c) SPREs but no IWB.

In the rest of this paper we further investigate the relationship between the different flow diagnostics used here. We focus on describing the temporal evolution of the ridge events, so that we can suggest precursors and mechanisms associated with the change in regime.

\section{b. Evolution of SPRE events}

We now examine the evolution with respect to the dynamical indices introduced above. Previous experience has shown that the onset day of RWB can be a very effective date about which to form composites, as the onset is clearly defined as the first day on which the gradient becomes irreversibly reversed (Woollings et al. 2008; Woollings and Hoskins 2008). The onset day is then defined as the first day that is part of an IWB after 5 consecutive days, which are not.
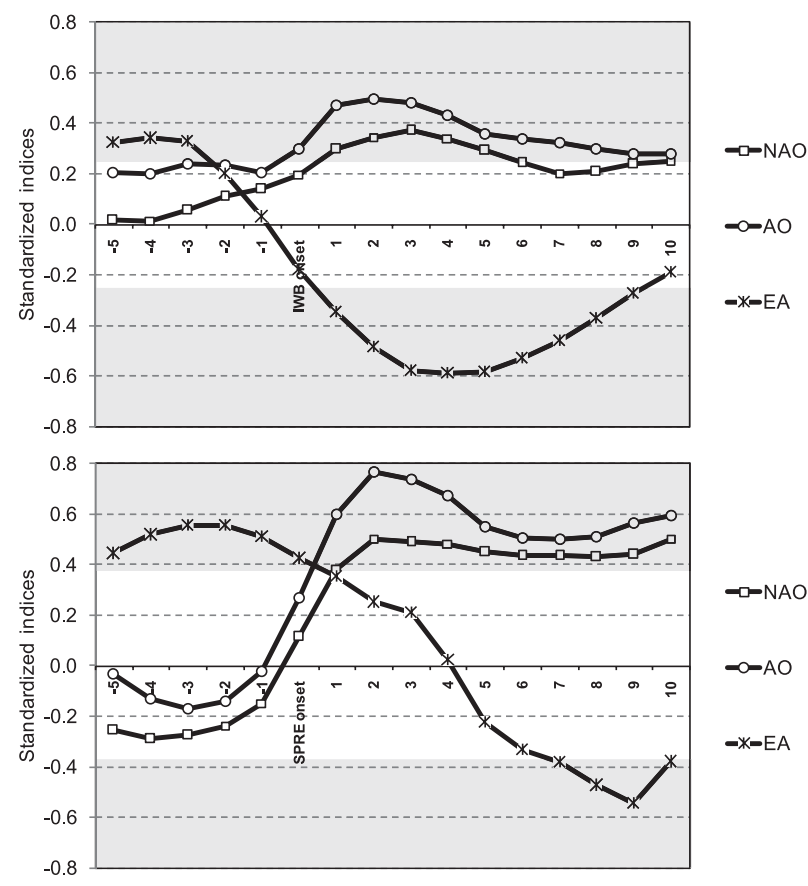

FIG. 4. Temporal evolution of the selected teleconnection indices (NAO, AO, and EA) considering the (top) IWB onsets (72 onsets) and (bottom) SPRE onsets (29 onsets) as time reference. Mean indices are plotted from 5 days before onset to 10 days after onset. For comparison, all indices are standardized to zero mean and unit variance (means and variances computed for the corresponding DJF distributions). Gray bands refer to the $95 \%$ confidence level.

Figure 4 shows the temporal evolution of several relevant teleconnection patterns [NAO, Arctic Oscillation (AO), and EA] composited using both the IWB and the SPRE onsets as a time reference (from 5 days before onset to 10 days after onset). The phase and amplitude of the teleconnection patterns are commonly quantified by indices; here the daily indices provided by the Climate Prediction Center (CPC; see online at http://www.cpc. noaa.gov/) were used. For the EA pattern no daily data was available, so the daily time series was obtained by projecting daily $500-\mathrm{hPa}$ geopotential heights from ERA-40 onto the EA spatial pattern as derived by CPC using rotated principal component analysis. This pattern was in turn obtained by regressing the monthly mean geopotential heights onto the monthly time series from CPC. These large-scale patterns have been described in many previous studies (e.g., Wallace and Gutzler 1981).

The negative anomalies westward of the British Isles (positive EA phase) start to weaken 2 days before IWB onset, while they are already reversed at the IWB onset (negative EA phase). This reveals that the IWB onset occurs when the anomalies are already building up (i.e., the strengthening of the North Atlantic ridge over the eastern North Atlantic tends to precede the IWB 
episodes). The positive anomalies (negative EA pattern) continue developing during the first 4 days of the IWB episodes, when the EA index reaches rather strong negative values (about -0.6 ), statistically significant at a $95 \%$ confidence level. After this period of maximum anomalies (3-5 days after onset), the negative EA phase gradually weakens.

The NAO and AO indices depict a similar temporal behavior, showing a clear strengthening of their positive phases after the IWB onset and reaching maximum values 2-3 days after the onset. This evolution is also consistent with the development of the anticyclonic ridge and of its corresponding positive anomalies over the eastern North Atlantic. The signal is weaker in the NAO than in the AO index, perhaps because the NAO is approximately orthogonal to the EA pattern that already incorporates much of the variability. No significant link is detected for the Pacific-North American (PNA) pattern (not shown).

A similar approach was also followed for the SPRE onsets. The temporal evolution of the indices is in general agreement with that for the IWB onsets. However, there is an offset of 5-6 days in the reversing of the EA index, which suggests that the IWB episodes tend to be preceded by the strengthening of the positive height anomalies over the eastern North Atlantic and the resulting establishment of the SPRE.

Figure 5 summarizes the behavior of the different indices with respect to IWB onset. This shows that in many cases the jet stream begins to shift northward 3 or 4 days before the onset of IWB. Similarly there are several SPRE onsets that occur in the period immediately before IWB onset. It is natural that a wave must amplify before it can break, and these results show that the anomalies can be large enough to qualify as a SPRE before the wave actually breaks. The role of the RWB then seems to be to amplify the disturbance and to increase its persistence (Croci-Maspoli et al. 2007). The spread in jet stream location is reduced over the period of at least 2 weeks before IWB onset. That the jet is not displaced northward in this period is a reflection of the definition of IWB onset, but interestingly the jet is also less likely to be displaced southward. This feature is significant, as shown later, and is encouraging for the prospects of predictability. It suggests a preconditioning of the large-scale circulation before IWB onset, which could reflect an intrinsic time scale of longer than a few days for jet stream shifts. Similarly, after the IWB event it is around 20 days before the likelihood of a southward shifted jet returns to its long-term value.

\section{c. Dynamical analysis}

In the rest of this section we describe the dynamical evolution of SPRE events more generally. Figure 6 shows

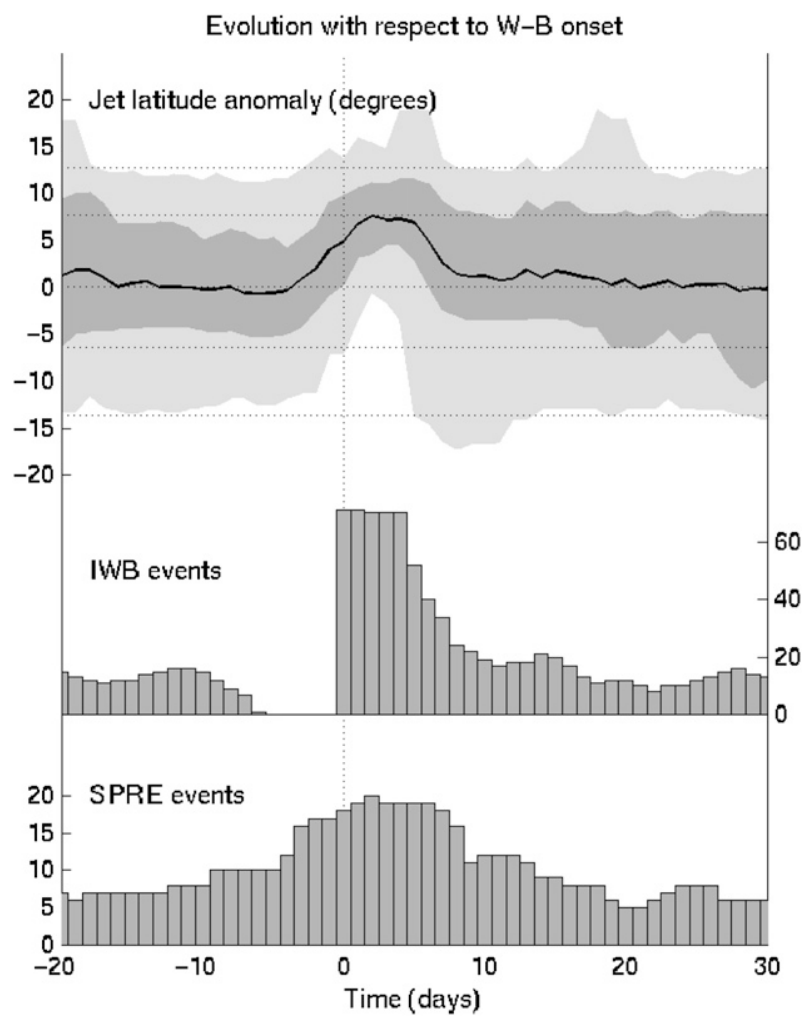

FIG. 5. Comparison of the timing of events as identified by different indices, centered with respect to the onset dates of the IWB events. (bottom) Histograms show the number of IWB and SPRE events occurring in the period around IWB onset. (top) The jet latitude is also composited over the same time period, with the mean (black line), 25\%-75\% (dark shading) and 5\%-95\% (light shading) ranges across the set of events shown. Horizontal lines mark the climatological values of these percentiles.

the 250-hPa streamfunction composited over the period 5-10 days before the IWB onset dates. First, there are significant anomalies in the North Atlantic that project in particular onto the positive phase of the NAO. This confirms that the jet stream is unlikely to be shifted southward over an extended period prior to IWB onset. This implies a certain lag in the system, in that it takes several days for the jet stream to shift from a southern position to a northern position. Second, there is a clear Rossby wave train pattern arching from the Pacific into the Atlantic. Several studies have shown that the propagation of wave activity from the Pacific to the Atlantic can be an important factor in the onset of jet stream regimes in the North Atlantic (Franzke et al. 2004; Strong and Magnusdottir 2008a,b; Cassou 2008; Lin et al. 2009; Pinto et al. 2011).

Figure 7 shows the subsequent evolution of the streamfunction. By day -3 the wave has decayed over the Pacific, but there is a remnant of it across southern North America and this contributes to the cyclonic 


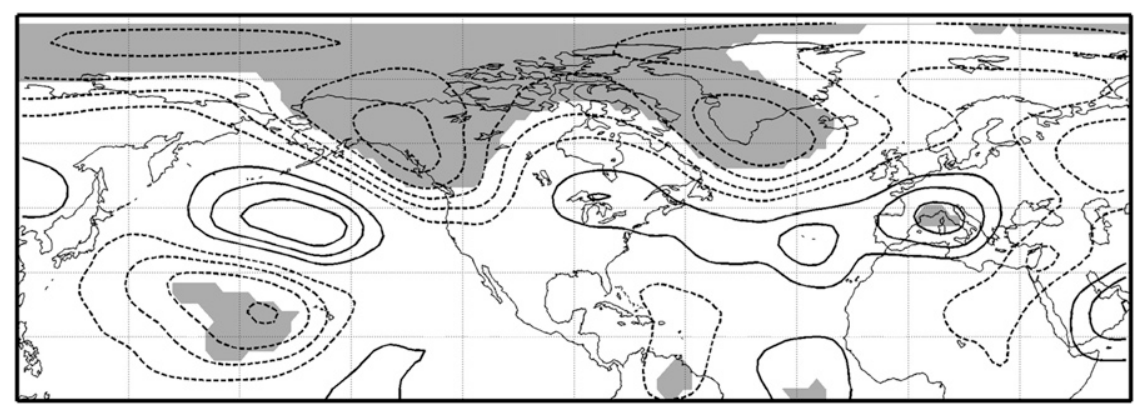

FIG. 6. 250-hPa streamfunction anomalies composited over the period 5-10 days before IWB onset. The contour interval is $1 \times 10^{6} \mathrm{~m}^{2} \mathrm{~s}^{-1}$, with negative (cyclonic) contours dashed and the zero contour omitted. Shading indicates anomalies that are not consistent with sampling noise at the $95 \%$ level, according to a two-sided Monte Carlo resampling test with 1000 trials in which 72 "onset dates" are chosen at random.

anomaly which builds in the southern North Atlantic over the following days. It is not clear whether this relatively weak direct contribution to the developing SPRE anomaly pattern is the extent of the influence of the wave train.

It is well known that low-frequency flow variations are accompanied by variations in the high-frequency transient eddy field (Wettstein and Wallace 2010) and that the transient eddies play a role in the maintenance of the low-frequency flow anomalies (e.g., Branstator 1995). There is also evidence that variations in transient eddy forcing often contribute to the development of the largescale flow anomalies (e.g., Lorenz and Hartmann 2003; Vallis et al. 2004; Roebber 2009), although in some analyses their role appears minor (Athanasiadis and Ambaum 2010). We investigate the role of transient eddy forcing in the temporal evolution of the SPRE events by using 2-6day bandpass-filtered winds (Duchon 1979). Figure 7 also shows the transient eddy kinetic energy derived from these filtered wind fields. This shows a clear increase in eddy activity in the few days immediately preceding IWB onset. This suggests that variations in the transient eddy forcing are important in causing the onset of SPRE events. Interestingly, the eddy kinetic energy anomalies develop in situ in the North Atlantic, so there is no evidence of a propagation of transient wave packets from the Pacific, as has been seen in other situations (Franzke et al. 2004). One possibility is that the remnants of the low-frequency Pacific wave train act to enhance the Atlantic transient eddy activity, perhaps by encouraging advection of air along the strong baroclinic zone over the east coast of North America (cf. Pinto et al. 2011).

To further clarify the role of the transient eddy activity, we calculate the $\mathbf{E}$ vectors defined by Hoskins et al. (1983). These describe the effects of transient eddy momentum fluxes on the mean flow. Figure 8 a shows the 250-hPa zonal wind anomalies seen during IWB events, and also the divergence of the $\mathbf{E}$ vectors for the 5-day period centered on the IWB onset dates. Regions of positive divergence indicate where the 2-6-day eddy field acts to accelerate the westerly wind, so it is clear that the eddies are acting in the same sense as the wind anomalies. Figure $8 \mathrm{~b}$ then shows the evolution of the eddy forcing, as the projection of $\boldsymbol{\nabla} \cdot \mathbf{E}$ for each day onto the wind pattern in Fig. 8a. There is a large positive projection of eddy forcing onto the wind anomaly pattern centered on the onset day of IWB, showing that the transient eddies contribute to the onset of the IWB event. The projection remains significantly positive for the 15 days following onset, showing that at this stage the eddies help to maintain the large-scale anomaly pattern. This is in agreement with the concept of a positive eddy feedback, in which the large-scale flow organizes the eddies in such a way that the associated eddy forcing acts to reinforce the large-scale flow anomalies (Branstator 1995; Lorenz and Hartmann 2003; Robinson 2006; Gerber and Vallis 2007). The picture that emerges is that of a dual role of the transient eddies: they act on average to maintain the jet in its current position, but eddy variations, perhaps chaotic, can provide a strong initial forcing to displace the jet.

\section{Discussion and conclusions}

In this paper we analyzed the relationship between northward shifts of the eddy-driven jet, the establishment and maintenance of strong and persistent ridges in the subtropics (SPRE), and the occurrence of uppertropospheric anticyclonic RWB over Iberia (IWB). In addition, we relate the occurrence of this regime with shifts in the phase of the North Atlantic Oscillation and the East Atlantic pattern, and analyze the role of transient eddy forcing and RWB in the evolution and maintenance of the events. Our results show that SPREs do coincide with both northward displacements of the 


\section{Day -3}

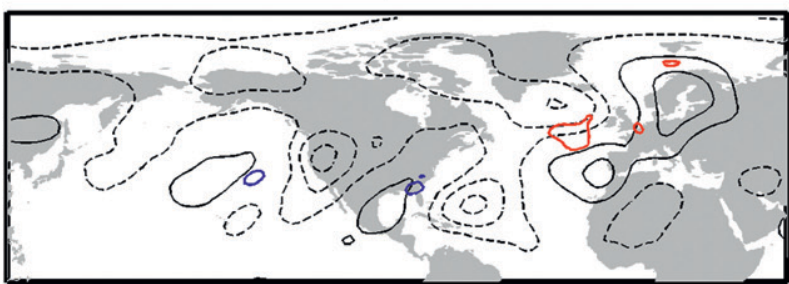

Day -2

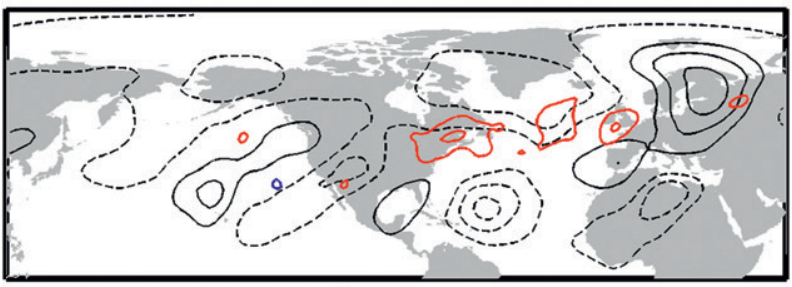

Day -1

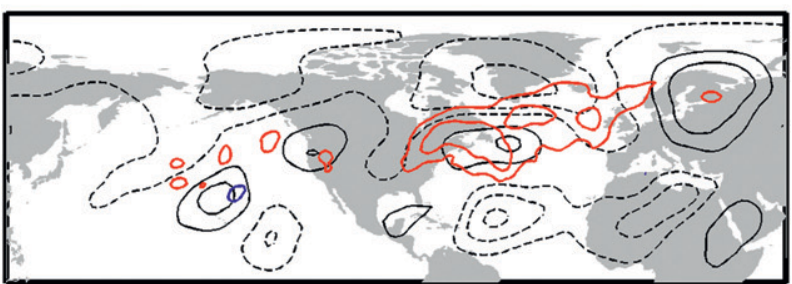

Day 0

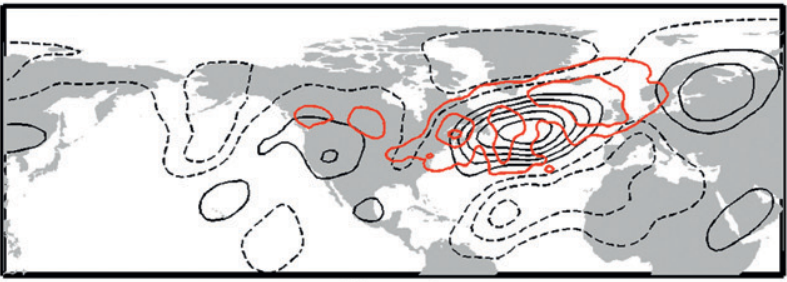

Day 1

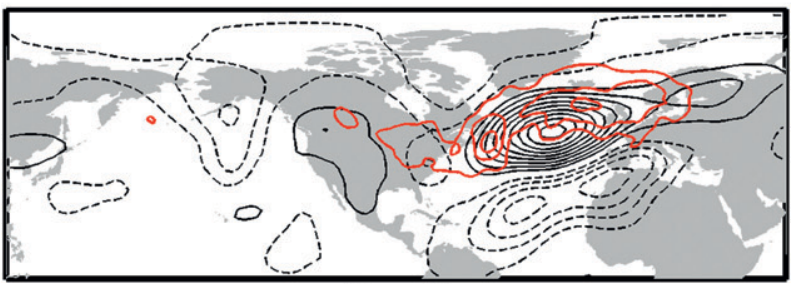

Day 2

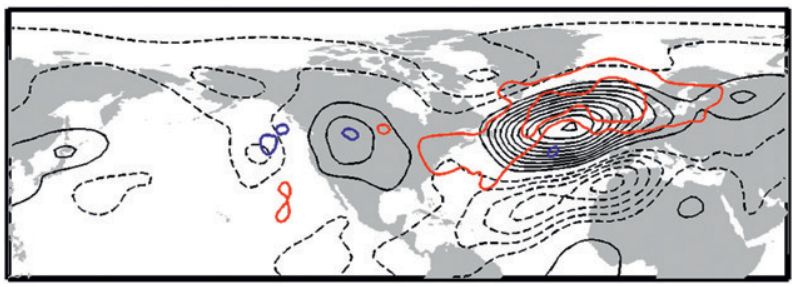

FIG. 7. Evolution of daily anomalies of the 250-hPa streamfunction and 2-6-day transient eddy kinetic energy composited with respect to the IWB onset dates. The streamfunction is contoured every $2 \times$ $10^{6} \mathrm{~m}^{2} \mathrm{~s}^{-1}$, with negative (cyclonic) contours dashed and the zero contour omitted. The eddy kinetic energy is contoured every $20 \mathrm{~m}^{2} \mathrm{~s}^{-2}$, with negative values in blue and positive values in red. a) $\nabla \cdot E$ (onset-2 : onset+2) and zonal wind anomalies
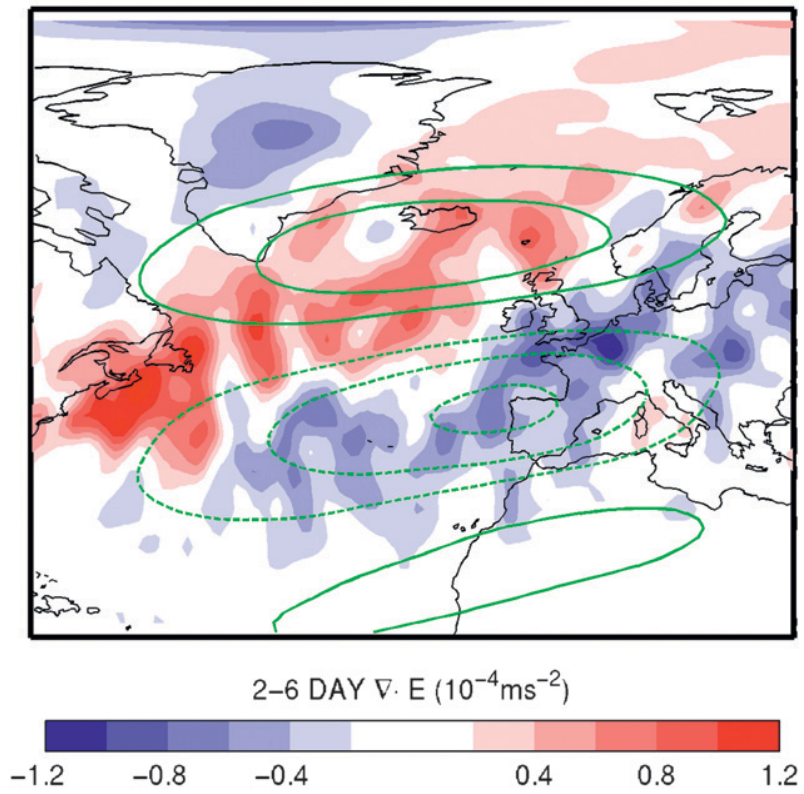

b) Projection of $\nabla \cdot E$ on $U$ anomaly

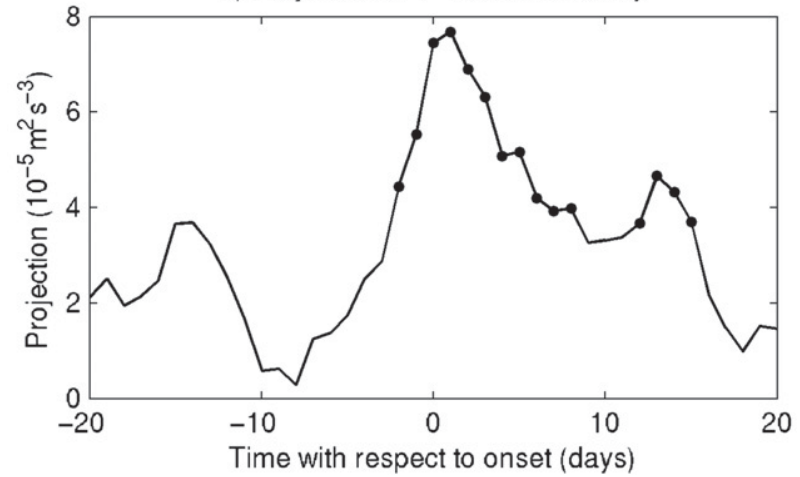

FIG. 8. (a) Divergence of the $\mathbf{E}$ vectors calculated from the 2-6day-filtered winds, shown by shading as anomalies composited over days -2 to +2 with respect to the onset dates of IWB. Contours show the zonal wind anomaly during IWB events at a $5 \mathrm{~m} \mathrm{~s}^{-1}$ contour interval, with negative contours dashed and the zero contour omitted. (b) The evolution of the projection of the daily E-vector divergence onto the wind anomalies in (a). The projection is calculated as an area-weighted scalar product over the region $0^{\circ}-90^{\circ} \mathrm{N}, 75^{\circ} \mathrm{W}-15^{\circ} \mathrm{E}$. Day 0 is the onset of IWB.

Atlantic eddy-driven jet stream and also with persistent IWB episodes. In the period immediately before the onset of IWB, the jet stream is already displaced to the north. Indeed, the occurrence of a SPRE event is generally detected before the onset of IWB (Fig. 5). This suggests that the role of IWB events is to amplify the existing anomaly pattern and likely to enhance its persistence (Masato et al. 2009). It is the persistence criterion that separates SPREs from other northern jet 
events, and our analysis shows that it is rare for a ridge to qualify as a SPRE without an accompanying IWB occurrence.

It is interesting to compare these results with those of Woollings et al. (2008) who used the same wavebreaking index to examine the relation between Greenland blocking episodes (GBEs) and negative NAO events. In contrast to the results presented here, the period immediately before GBE onset is characterized by circulation anomalies of the opposite sign to those seen during the event itself, suggesting that in that case the RWB is critical in establishing the anomalous flow (e.g., see Fig. 7 in Woollings et al. 2008). Consistent with Woollings et al. $(2008,2010 b)$ the IWB events appear to be less critical for northward displacements of the jet than GBE events are for southward displacements. This is also consistent with the behavior found by Rivière (2010) associated with the West Pacific pattern, which is analogous to the NAO. In this case it also appears that wave breaking is involved in triggering southward jet shifts as well as maintaining them, but is only involved in the maintenance of northward shifts. In contrast, several studies have concluded that RWB plays a key role in the onset of northward jet displacements (e.g., Benedict et al. 2004; Strong and Magnusdottir 2008b). This apparent contradiction may simply reflect the focus here on persistent RWB events which qualify as blocking-like situations, rather than LC1-type wave-breaking events, which are shorter lived (e.g., Kunz et al. 2009b).

We have also shown that the transient (2-6 day) eddies play a dual role in both initiating and maintaining the large-scale circulation anomalies. The implied positive feedback between the jet stream anomalies and the transient eddies contributes to the persistence of the SPREs. However, note that several studies have now shown that northward-displaced jet events such as the SPREs are less persistent than southward-shifted events (Barnes and Hartmann 2010a,b; Woollings et al. 2010b; Barnes et al. 2010).

There are clear tropospheric precursors to northward jet displacements, consisting of Atlantic jet stream anomalies and a large-scale Rossby wave train from the North Pacific basin. Even though the SPREs have been shown to be already building by the onset of the IWB events, the IWB onset dates have proved useful dates about which to composite events. This is perhaps because the first day that the meridional potential temperature gradient reverses is very clearly and objectively defined.

While in this paper we have focused on tropospheric precursors, Santos et al. (2009) also showed that the stratospheric polar vortex is unusually strong, and deformed over North America, in the period prior to the onset of SPREs. Interestingly, such a stratospheric precursor appears distinct from the Northern Annular Mode signal (e.g., Baldwin and Dunkerton 2001). It remains to be seen to what extent this stratospheric precursor can be explained as a dynamical response to the tropospheric precursors, which will act to modify the stationary wave pattern and hence the upward propagation of long Rossby waves into the stratosphere. Both the stratospheric and tropospheric precursors have implications for the predictability of northward displacements of the eddy-driven jet stream and of SPRE events; for example, they provide useful tests for the skill of numerical models used in forecasting.

Finally we note that the impact of anthropogenic climate change on the occurrence of high-impact weather events associated with northward displacements of the Atlantic eddy-driven jet stream such as SPREs is of great interest. There are indications from some climate models that the shape of the distribution of NAO variability may change in the future such that the positive phase of the NAO occurs relatively more frequently (Coppola et al. 2005; Stephenson et al. 2006; Woollings et al. 2010a). This motivates further work in this area in the future, in particular on the ability of current climate models to simulate the dynamics of jet stream variability.

Acknowledgments. We are indebted to the European Centre for Medium-Range Weather Forecasts for providing the ERA-40 reanalysis data. We would also like to thank the two anonymous reviewers for their constructive comments, which have helped to improve this manuscript.

\section{REFERENCES}

Athanasiadis, P. J., and M. H. P. Ambaum, 2010: Do high-frequency eddies contribute to low-frequency teleconnection tendencies? J. Atmos. Sci., 67, 419-433.

Baldwin, M. P., and T. J. Dunkerton, 2001: Stratospheric harbingers of anomalous weather regimes. Science, 294, 581-584.

Barnes, E. A., and D. L. Hartmann, 2010a: Dynamical feedbacks and the persistence of the NAO. J. Atmos. Sci., 67, 851-865.

- and $-2010 \mathrm{~b}$ : Influence of eddy-driven jet latitude on North Atlantic jet persistence and blocking frequency in CMIP3 integrations. Geophys. Res. Lett., 37, L23802, doi:10.1029/ 2010GL045700.

,-- D. M. W. Frierson, and J. Kidston, 2010: The effect of latitude on the persistence of eddy-driven jets. Geophys. Res. Lett., 37, L11804, doi:10.1029/2010GL043199.

Benedict, J. J., S. Lee, and S. B. Feldstein, 2004: Synoptic view of the North Atlantic oscillation. J. Atmos. Sci., 61, 121-144.

Branstator, G., 1995: Organization of storm track anomalies by recurring low-frequency circulation anomalies. J. Atmos. Sci., 52, 207-226.

Cassou, C., 2008: Intraseasonal interaction between the MaddenJulian Oscillation and the North Atlantic Oscillation. Nature, 455, 523-527, doi:10.1038/nature07286. 
Coppola, E., F. Kucharski, F. Giorgi, and F. Molteni, 2005: Bimodality of the North Atlantic Oscillation in simulations with greenhouse gas forcing. Geophys. Res. Lett., 32, L23709, doi:10.1029/2005GL024080.

Croci-Maspoli, M., C. Schwierz, and H. C. Davies, 2007: Atmospheric blocking: Space-time links to the NAO and PNA. Climate Dyn., 29, 713-725.

Duchon, C. E., 1979: Lanczos filtering in one and two dimensions. J. Appl. Meteor., 18, 1016-1022.

Feldstein, S. B., 2003: The dynamics of NAO teleconnection pattern growth and decay. Quart. J. Roy. Meteor. Soc., 129, 901-924.

Franzke, C., S. Lee, and S. B. Feldstein, 2004: Is the North Atlantic Oscillation a breaking wave? J. Atmos. Sci., 61, 145-160.

Gabriel, A., and D. Peters, 2008: A diagnostic study of different types of Rossby wave breaking events in the northern extratropics. J. Meteor. Soc. Japan, 86, 613-631.

Gerber, E. P., and G. K. Vallis, 2007: Eddy-zonal flow interactions and the persistence of the zonal index. J. Atmos. Sci., 64, 32963311.

Hoskins, B. J., I. James, and G. H. White, 1983: The shape, propagation, and mean flow interaction of large-scale weather systems. J. Atmos. Sci., 40, 1595-1612.

Kistler, R., and Coauthors, 2001: The NCEP-NCAR 50-Year Reanalysis: Monthly means CD-ROM and documentation. Bull. Amer. Meteor. Soc., 82, 247-267.

Kunz, T., K. Fraedrich, and F. Lunkeit, 2009a: Impact of synopticscale wave breaking on the NAO and its connection with the stratosphere in the ERA-40 reanalysis. J. Climate, 22, 5464-5480.

,-- , and $-2009 \mathrm{~b}$ : Synoptic wave-breaking and its potential to drive NAO-like circulation dipoles: A simplified GCM approach. Quart. J. Roy. Meteor. Soc., 135, 1-19.

Lin, H., G. Brunet, and J. Derome, 2009: An observed connection between the North Atlantic Oscillation and the MaddenJulian oscillation. J. Climate, 22, 364-380.

Lorenz, D. J., and D. L. Hartmann, 2003: Eddy-zonal flow feedback in the Northern Hemisphere winter. J. Climate, 16, 1212-1227.

Martius, O., C. Schwierz, and H. C. Davies, 2007: Breaking waves at the tropopause in the wintertime Northern Hemisphere: Climatological analyses of the orientation and the theoretical LC1/2 classification. J. Atmos. Sci., 64, 2576-2592.

Masato, G., B. J. Hoskins, and T. J. Woollings, 2009: Can the frequency of blocking be described by a red noise process? $J$. Atmos. Sci., 66, 2143-2149.

Monahan, A. H., J. C. Fyfe, M. H. P. Ambaum, D. B. Stephenson, and G. R. North, 2009: Empirical orthogonal functions: The medium is the message. J. Climate, 22, 6501-6514.

Pelly, J. L., and B. J. Hoskins, 2003: A new perspective on blocking. J. Atmos. Sci., 60, 743-755.

Pinto, J. G., M. Reyers, and U. Ulbrich, 2011: The variable link between PNA and NAO in observations and in multi-century CGCM simulations. Climate Dyn., 36, 337-354, doi:10.1007/ s00382-010-0770-x.

Rivière, G., 2010: The role of Rossby wave-breaking in the West Pacific teleconnection. Geophys. Res. Lett., 37, L11802, doi:10.1029/2010GL043309.
- , and I. Orlanski, 2007: Characteristics of the Atlantic stormtrack eddy activity and its relation with the North Atlantic Oscillation. J. Atmos. Sci., 64, 241-266.

Robinson, W. A., 2006: On the self-maintenance of midlatitude jets. J. Atmos. Sci., 63, 2109-2122.

Roebber, P. J., 2009: Planetary waves, cyclogenesis, and the irregular breakdown of zonal motion over the North Atlantic. Mon. Wea. Rev., 137, 3907-3917.

Santos, J. A., J. Corte-Real, and S. M. Leite, 2005: Weather regimes and their connection to the winter rainfall in Portugal. Int. J. Climatol., 25, 33-50.

— J. G. Pinto, and U. Ulbrich, 2009: On the development of strong ridge episodes over the Eastern North Atlantic. Geophys. Res. Lett., 36, L17804, doi:10.1029/2009GL039086.

Stephenson, D. B., V. Pavan, M. Collins, M. M. Junge, and R. Quadrelli, 2006: North Atlantic Oscillation response to transient greenhouse gas forcing and the impact on European winter climate: A CMIP2 multi-model assessment. Climate Dyn., 27, 401-420.

Strong, C., and G. Magnusdottir, 2008a: How Rossby wave breaking over the Pacific forces the North Atlantic Oscillation. Geophys. Res. Lett., 35, L10706, doi:10.1029/2008GL033578.

_ and 2 2008b: Tropospheric Rossby wave breaking and the NAO/NAM. J. Atmos. Sci., 65, 2861-2876.

Tyrlis, E., and B. J. Hoskins, 2008: The morphology of Northern Hemisphere blocking. J. Atmos. Sci., 65, 1653-1665.

Ulbrich, U., M. Christoph, J. G. Pinto, and J. Corte-Real, 1999: Dependence of winter precipitation over Portugal on NAO and baroclinic wave activity. Int. J. Climatol., 19, 379-390.

Uppala, S. M., and Coauthors, 2005: The ERA-40 Reanalysis. Quart. J. Roy. Meteor. Soc., 131, 2961-3012.

Vallis, G. K., E. P. Gerber, P. J. Kushner, and B. A. Cash, 2004: A mechanism and simple dynamical model of the North Atlantic Oscillation and annular modes. J. Atmos. Sci., 61, 264-280.

Wallace, J. M., and D. S. Gutzler, 1981: Teleconnections in the geopotential height field during the Northern Hemisphere winter. Mon. Wea. Rev., 109, 784-812.

_- G.-H. Lim, and M.-L. Blackmon, 1988: Relationship between cyclone tracks, anticyclone tracks and baroclinic waveguides. J. Atmos. Sci., 45, 439-462.

Wettstein, J. J., and J. M. Wallace, 2010: Observed patterns of month-to-month storm track variability and their relationship to the background flow. J. Atmos. Sci., 67, 1420-1437.

Woollings, T., and B. Hoskins, 2008: Simultaneous Atlantic-Pacific blocking and the Northern Annular Mode. Quart. J. Roy. Meteor. Soc., 134, 1635-1646.

, - M. Blackburn, and P. Berrisford, 2008: A new Rossby wave-breaking interpretation of the North Atlantic Oscillation. J. Atmos. Sci., 65, 609-626.

A. Hannachi, B. Hoskins, and A. Turner, 2010a: A regime view of the North Atlantic Oscillation and its response to anthropogenic forcing. J. Climate, 23, 1291-1307.

,$- \ldots$, and,$- 2010 \mathrm{~b}$ : Variability of the North Atlantic eddydriven jet stream. Quart. J. Roy. Meteor. Soc., 136, 856-868. 